\title{
Zip to Industry: A First-Year Corporate-STEM Connection Program
}

\section{Dr. Donald P. Visco Jr., The University of Akron}

Donald P. Visco, Jr. is the former Dean of the College of Engineering at The University of Akron and currently a Professor of Chemical Engineering.

\section{Nidaa Makki}

Dr. Nidaa Makki is an Associate Professor in the LeBron James Family Foundation College of Education at The University of Akron, in the department in Curricular and Instructional Studies. Her work focuses on STEM curriculum integration and science inquiry practices in middle and high school. She is a co-PI on an NSF funded project to investigate the impact of integrating engineering on middle school students' interest and engagement in STEM. She has also received funding to conduct teacher professional development in the areas of engineering education, problem based learning and inquiry instruction.

Dr. Linda M Subich, The University of Akron

Distinguished Professor of Psychology and currently Interim Dean, Buchtel College of Arts \& Sciences at The University of Akron

Prof. David Steer, The University of Akron

Ms. Erin R Stevic, The University of Akron 


\section{Zip to Industry: A First-Year Corporate-STEM Connection Program}

\section{Introduction}

Student motivation towards a STEM career is an area of active research with many varied approaches attempted to increase interest in a STEM major. Typical approaches include coursework (e.g. Project Lead The Way), robotics programs (e.g. FIRST), STEM exposure days (e.g. STEM Career Day), hands-on outreach to local schools, etc. Indeed, approaches to motivate often do not stop even when STEM students are on campus, with first-year disciplinary courses including hands-on activities aimed at cultivating interest and motivation for that major.

While education and exposure are important steps, many students in STEM areas still have little idea of what would be a "typical day" for them at the workplace (once they graduate). Accordingly, the University of Akron has developed the "Zip to Industry: A First-Year Corporate-STEM Connection program”. This program connects first-year STEM students with co-op/intern students within their major (or in a similar major) for several four-hour job shadowing experiences during their initial year on campus.

The purpose of this study is to investigate the impact a first-year STEM job-shadowing program on first-year students' retention in STEM, and their knowledge of careers in STEM fields. The study reported in this paper is part of a larger study that is also investigating the relationship between self-efficacy, interest in STEM, and retention.

\section{Theory of Action}

The use of shadowing experiences for first-year STEM students as a means to make progress on the research questions of this project is grounded in Social Cognitive Career Theory (SCCT) [1], [2]. In short, SCCT states that an individual's efforts towards reaching a goal are functions of their interest, confidence and outcome expectation. The latter two (confidence and outcome expectation) are then functions of an individual's prior learning experiences.

As it relates to the current project, the theory implies that the shadowing experiences would enhance positive outcome expectations regarding a STEM career, as well as self-efficacy expectations for success. This, in turn, would result in a strengthened commitment and persistence to their chosen STEM major.

Literature exists to support the tenets of Social Cognitive Career Theory [3]. SCCT has shown to be a useful framework in areas of academic performance and persistence [4], for predicting interests and goals of engineering students [5], and for goals of underrepresented STEM students [6]. 
The use of shadowing experiences (or vicarious learning) has been shown to relate to selfefficacy, outcome expectation and career related outcomes for individuals [7], [8]. This includes the use of shadowing experience to enhance occupational knowledge and commitment, as well as promote achievement and persistence in STEM careers [9]. Some research has also suggested the value of job shadowing for enhancing underrepresented students' STEM career interest [6].

\section{Program Overview}

The program was focused on one-on-one shadowing experiences for first-year students with other junior/senior students from the same institution who were already on cooperative education/internship assignments at a company. Experiences were held almost exclusively on Fridays and were, on average, four hours in length.

Participants received a \$10/hour stipend for completing job shadowing and reimbursement for transportation (either roundtrip mileage driving or fees for using a ride-sharing service.) Students were responsible for providing their own transportation to and from experiences, with participating employers located within a 60-mile range of the University of Akron. On rare occasions when students did not have transportation, they used ride-sharing companies to take them to and from a shadowing experience.

The program team met with a sample of representatives from those companies who committed to the project to discuss logistics in advance of the first assignments (Fall 2018). In particular, almost all shadowing experiences would be held on Fridays and would be for up to four hours. In alignment with SCCT, the program team also emphasized the following key guidelines for the shadowing experiences:

- Place of work. It was emphasized that the first-year student experience the place of work of the shadowed employee, whether it is a smaller office space or a larger facility. Thus, a tour led by the shadowed employee is appropriate. This also provided a great opportunity for the company to educate the first-year student on their business and its value for a prospective employee. Where applicable and accessible, the first-year students met several employees at the job site, instead of just the shadowed employee.

- Task observation. It was crucial for the first-year student to observe the shadowed employee performing typical job functions of their position. Whether it is working on the computer or a piece of equipment, talking to colleagues or clients about an issue or participating in meetings, the first-year student needed to see many elements of "a typical day". Companies were encouraged to involve the first-year student in the actual activity (i.e. a hands-on experience) when possible. This could be experiencing a piece of equipment or even participating in a discussion to share their ideas. The team explained that the more involvement the first-year student has with the actual experience of the 
shadowed employee, the better the chance that their confidence and comfort will increase.

- Discussion and interaction with the shadowed employee. Since it seemed likely that for much of the time the first-year student would be engaged in conversation with the shadowed employee, this interaction and what would be discussed can have a large impact on the success of shadowing experiences for the first-year student. To that end, the shadowed employees were encouraged to share (at least) the following information with the first-year student during their discussion:

a. What they find desirable or valuable in the job setting (in terms of their long range career path).

b. How they transitioned from a first-year student to a co-op/intern student in terms of school performance and motivation.

c. Challenges they may have had from a persistence standpoint (e.g. bouncing back from a poor grade on an assignment, quiz or test).

d. How their co-op/internship experience is part of their strategy to reach their ultimate goal (whether full-time employment, graduate school, etc.)

Additionally, it was important in all the items above that the shadowed employee asks the first-year student about their thoughts and opinions as it relates to goal setting, meeting challenges and persistence strategies.

It is noted that 80 companies initially responded to the call for support of the program and 49 of those companies participated in the program during this first-year. An additional 16 companies provided job shadowing opportunities for students even though they did not originally write support letters for this project.

\section{Methods}

\section{Student Selection}

During Spring 2018, the program team identified matriculating high school students who were entering the University of Akron as STEM majors beginning in Fall 2018. Following these students' New Student Orientation, the Project Coordinator sent each student an email introducing the program and encouraging them to complete a Qualtrics questionnaire. This survey asked students about their preparation and motivation for a STEM career through the following factors: a) commitment to major; b) motivation for their intended career; c) confidence in their ability to succeed in their intended career; d) outcome expectations for their career; e) other career interests; f) perceived barriers to their career choice; g) role models in STEM areas; h) experiential learning in STEM areas; i) previous shadowing experiences; j) immediate family members in STEM careers; k)participation in special HS courses (pre-engineering-PLTW, pretechnology, etc.)

One thousand seventy-two (1072) first-year STEM students received an invitation e-mail along with an online survey link. The team did not include biology or biomedical science, in the 
survey outreach because shadowing experiences were not available in these fields for Year 1. Twenty-five percent (277) of the students completed the survey.

In August 2018, the program team randomly selected 60 first-year students to participate in the intervention cohort from a selected pool of students who completed the online survey. Initially, the pool was reduced to the target population of students who completed at least $70 \%$ of the survey, were 18 years or older on the first day of shadowing and had an ACT range between 20 and 29. This reduced the pool to 189 students. From analysis of prior retention data at the institution, we found that STEM students with a composite ACT score of 30 and above are retained in STEM at such a high rate that the impact of the intervention would be very limited. Likewise, students with a composite ACT score of lower than 20 are retained in STEM at a low rate and, thus, the intervention may be insufficient to help a significant number of these underprepared students succeed in STEM. Next, we randomly selected 60 students from this pool, while oversampling for female students and minority students.

The Program Coordinator contacted selected students via email to offer them places in the intervention cohort. If a student declined a place in the intervention cohort, the team selected an alternate student from the pool of eligible students based on the selection criteria. Students who declined a place in the cohort cited either a lack of transportation to shadowing experiences or timing conflicts (work or class) that would make them unable to complete the required shadowing experiences. This resulted in a final cohort of 59 students.

We selected a matched comparison group of 59 students from the one-hundred eleven (111) eligible students who were not selected for the intervention group, using gender, race, and major as selection variables. Table 1 presents a summary of the demographics of the intervention and comparison groups.

At the beginning of the intervention, there was no statistically significant difference between the two groups on ACT scores, and high school GPA.

Working with the selected intervention students, the program team and Career Services staff trained them in September 2018 to prepare them for their shadowing experiences. Training included sessions on professional soft skills, shadowing procedures, and resume building. Additionally, the program team created a short video for those co-op/intern students who would be shadowed students to watch ahead of their experiences.

During Fall 2018 and Spring 2019, the 59 students assigned to the intervention group completed a total of 197 shadowing experiences at 65 different employers. Seven employers hosted shadowing students during both fall and spring semesters. The number of shadowing experiences ranged from $1-7$, with a mean of 3.54. The variation in the number of experiences was mostly due to scheduling constraints. 
Table 1. Demographic characteristics of intervention and comparison groups.

\begin{tabular}{|c|c|c|c|c|}
\hline DEMOGRAPHIC & \multicolumn{2}{|c|}{ Comparison Students } & \multicolumn{2}{|c|}{ Intervention Students } \\
\hline \multicolumn{5}{|l|}{ Gender } \\
\hline Male & 30 & $50.8 \%$ & 30 & $50.8 \%$ \\
\hline Female & 27 & $45.8 \%$ & 29 & $49.2 \%$ \\
\hline Did not report/other & 2 & $3.4 \%$ & 0 & $0 \%$ \\
\hline \multicolumn{5}{|l|}{ Race/Ethnicity } \\
\hline White/Non-Hispanic & 49 & $83.1 \%$ & 49 & $83.1 \%$ \\
\hline Black/African American & 4 & $6.8 \%$ & 2 & $3.4 \%$ \\
\hline Asian American & 2 & $3.4 \%$ & 2 & $3.4 \%$ \\
\hline Bi-racial & 2 & $3.4 \%$ & 2 & $3.4 \%$ \\
\hline Hispanic & 2 & $3.4 \%$ & 4 & $6.8 \%$ \\
\hline All minorities & 10 & $16.9 \%$ & 10 & $16.9 \%$ \\
\hline Total & 59 & $50 \%$ & 59 & $50 \%$ \\
\hline
\end{tabular}

\section{Data Collection}

Mentors, mentees, and comparison students were asked to complete several surveys during the academic year to gather research and evaluation data for the program. Data collection procedures were reviewed and approved by the University of Akron Institutional Review Board. Consent procedures were included in the first page of the online survey.

A pre and post survey focusing on knowledge, preparation and motivation for a STEM career, adapted from work by [6], was administered to both groups. In addition, feedback on the shadowing experiences was collected from intervention students and shadowed employees after each experience using a Qualtrics (online survey tool) questionnaire. Intervention students were asked to list the activities they completed during shadowing. Common tasks (company tour, hands-on experience, reflection with co-op) were provided in a selection list and students could include details about additional activities in an open-ended text box. Students were asked to rate how they felt about the shadowing experience and how they felt about their interactions with 
their mentor (the shadowed employee). A text box was also provided for them to share other comments about the shadowing experience.

Shadowed employees were asked to list the activities completed during shadowing. They were also asked about their interactions with the intervention students, including if they explained the set of skills required by the profession, shared goal setting strategies, and shared information about their own experiences. The survey provided a text box where shadowed employees could leave other comments regarding the experience.

Retention and GPA data were collected through institutional research databases for the intervention and comparisons groups.

\section{Results}

Descriptive statistics were used to calculate frequencies of responses on surveys and means of subgroups. Inferential statistics were conducted to measure change and examine differences between the two groups. Analysis of retention data indicate that during the first-year of the intervention, students who participated in the program were retained in STEM at a higher rate compared to a matched sample of students who did not participate in the program $(81 \%$ compared to $63 \%)$, and the difference was statistically significant ( $\chi 2=5.09$, and $\mathrm{p}=.024)$. Retention was defined as students remaining in any STEM major (and not necessarily in the same STEM major). In addition, students in the program had achieved a significantly higher GPA than the comparison students, with a difference of .24 GPA points $(\mathrm{t}=5.590$, and $\mathrm{p}=0.020)$.

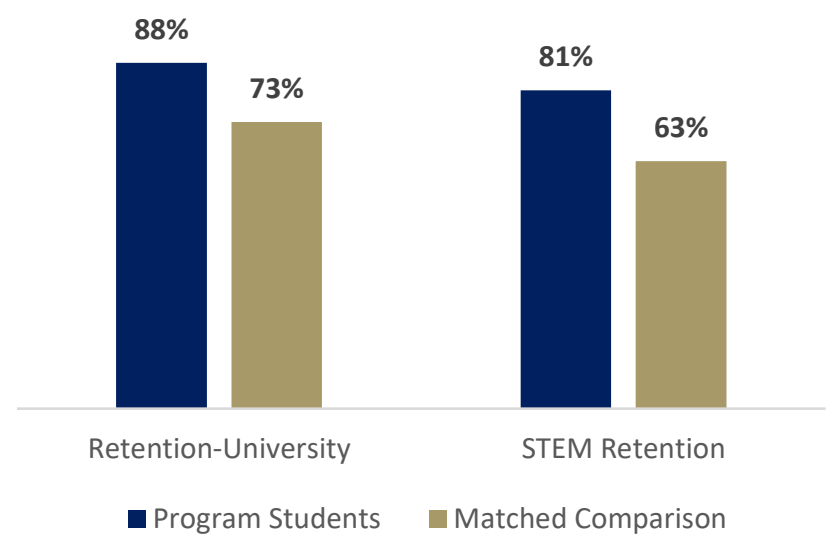

Figure 1. Comparison of retention rates between intervention and matched comparison group

The difference between the change scores from pre to post on the knowledge of STEM careers scale between the intervention group and comparison group was statistically significant $(\mathrm{p}=0.021)$, with the intervention group mean change of .67 points, on a Likert scale that ranges from 1 (not informed at all) to 4 (very well informed). The comparison group change from pre to 
post was not significant. These results are expected, as the intervention group had a targeted intervention focused on knowledge of STEM careers through job shadowing.

Students were also asked to report on the types of experiences they engaged in. A total of $83 \%$ reported taking a tour of the company, 63\% reported observing hands-on work, and $31 \%$ observed hands-on experiences. When asked about whether they spent time in reflection with the mentor about the experience, $64 \%$ of the students reported doing so.

Students were also asked about their satisfaction with their mentoring experiences. Overall, students reported high satisfaction with their experiences, with $90 \%$ stating that they are glad they did it, and $85 \%$ stating that they learned something new. Moreover, $78 \%$ stated that the experience makes them want to continue with their declared major.

In addition, students were asked about the quality of the mentoring experiences they received during their shadowing visits. The results indicated very positive interactions. The most positive interaction reported by ZTI students was that "the mentors shared information about their own experiences" (95.8\% either agreed or strongly agreed). The lowest reported interaction was "the mentor shared goal setting strategies" with only $56.3 \%$ reporting either agree or strongly agree to this item.

\section{Conclusion}

The purpose of this study was to investigate the impact of a job shadowing program on first-year students' retention in STEM. Preliminary results indicate positive impact on program participants in terms of retention in STEM majors, and at the university. We also found an increase in knowledge about STEM careers in comparison with first-year peers who did not participate in the program. Evaluation data also indicated that students were highly satisfied with the shadowing experiences. More research is needed to examine how the social cognitive factors such as coping, efficacy and outcome expectations are working to influence students' outcomes.

\section{References}

[1] R. W. Lent, S. D. Brown, and G. Hackett, "Toward a unified social cognitive theory of career/academic interest, choice and performance," Journal of Vocational Behavior, vol. 45, pp. 79-122, 1994.

[2] R. W. Lent, S. D. Brown, and G. Hackett, "Contextual supports and barriers to career choice: A social cognitive analysis," Journal of Counseling Psychology, vol. 47, pp. 36-49, 2000.

[3] H. B. Sheu, R. W. Lent, S. D. Brown, M. J. Miller, K. D. Hennessy, and R. D. Duffy, "Testing the choice model of social cognitive career theory across Holland themes: A meta-analytic path analysis," Journal of Vocational Behavior, vol. 76, pp. 252-264, 2000. 
[4] S. D. Brown, S. Tramayne, D. Hoxha, K. Telander, X. Fan, and R. W. Lent, "Social cognitive predictors of students' academic performance and persistence: A meta-analytic path analysis," Journal of Vocational Behavior, vol. 72, pp. 298-308, 2008.

[5] R. W. Lent, H. B. Sheu, D. Singley, J. A. Schmidt, L. C. Schmidt, and C. S. Gloster, "Longitudinal relations of self-efficacy to outcome expectations, interests, and major choice goals in engineering students," Journal of Vocational Behavior, vol. 73, pp. 328-335, 2008.

[6] A. Winston-Byars, Y. Estrada, C. Howard, D. Davis, and J. Zalapa, "Influence of social cognitive and ethnic variables on academic goals of underrepresented students in science and engineering: A multiple groups analysis," Journal of Counseling Psychology, vol. 57, pp. 205-218, 2010.

[7] P. O. Garriott, L. Y. Flores, B. Prabhakar, E. C. Mazzotta, A. C. Liskov, and J. E. Shapiro, "Parental Support and Underrepresented Students' Math/Science Interests: The Mediating Role of Learning Experiences," Journal of Career Assessment, vol. 22, pp. 627-641, 2014.

[8] A, K. McGonagle, H. C. Freake, S. Zinn, T. Bauerle, J. Winston, G. Jewicki, M. Jehnings, D. KhanBureau, and M. Philion, "Evaluation of STRONG-CT: A Program Supporting Minority and FirstGeneration U.S. Science Students," Journal of STEM Education: Innovations \& Research, vol. 15, pp. 52-61, 2014.

[9] N. Fouad, "Career linking: An intervention to promote math and science career awareness," Journal of Counseling and Development, vol. 73, pp. 527-534, 1995. 